\title{
PRONATOR QUADRATUS VASCULARIZED MUSCLE BONE PEDICLE GRAFT IN NONUNITED SCAPHOID FRACTURE WITH FIXATION
}

\author{
By
Ahmed Mohamed El-Naggar, Ibrahim Ahmed Hussein and Mohammed Ibrahim Aboul Seoud

Department of Orthopedic, Faculty of Medicine Al-Azhar University

Corresponding author: Ahmed Mohamed Elnaggar,

E-mail: ahmed.gaara88@gmail.com

\begin{abstract}
Background: Left untreated, scaphoid nonunion can progress to carpal collapse and a predictable pattern of radiocarpal arthrosis. The goals of surgery for scaphoid nonunion include uniting the fracture and restoring carpal alignment.

Objective: To assess the effect of pronator quadratus vascularized muscle bone pedicle graft in scaphoid nonunion with fixation.

Patients and Methods: The study was conducted on 20 patients with a history of scaphoid fracture since three months ago and no clinical or radiological signs of healing at Al-Azhar University Hospitals from January 2018 till February 2019. The patients underwent pronator quadratus vascularized muscle bone pedicle graft in scaphoid nonunion with fixation.

Results: The mean age of the studied cases was $34.27 \pm 11.74$ years and male predominance with all of the studied patients noted no complications wither early or late and returned to their previous level of activity. All the cases achieved bony union (100\%) in a mean of 12.5 weeks. There was improvement in mean radiolunate and scapholunate angles. Average range of motion and modified Mayo score. There were no early complications of surgical site infection or sensory disturbances in the area of the radial nerve. There were also none late septic complications. No radiographic progression of arthritis was noted in any patient within the available follow-up time. All patients returned to their previous level of activity and satisfied with the late clinical and functional results.

Conclusion: Volar vascularized bone grafts is an easy method and provides excellent results while needing no special equipment. Bone grafting is the mainstay treatment for non-union scaphoid. Vascularized bone grafts using pronator quadratus osteomuscular flaps have proved to be more biological and more successful treatment option.
\end{abstract}

Keywords: Pronator Quadratus Vascularized Muscle Bone Pedicle Graft, Nonunited Scaphoid Fracture with Fixation.

\section{INTRODUCTION}

Management of scaphoid nonunion is a challenging task for an orthopedic surgeon. Many surgical procedures have been employed, which reflects the lack of satisfaction or consistency with any one strategy (Kumar et al., 2017).

In cases of established nonunion, bone grafting is advocated to facilitate healing and correction of any carpal malalignment. Most important 
intraoperative step in the management of scaphoid nonunion is excision of the psudoarthrosis and fibrous scar tissue at the nonunion site. In doing so, a bony defect is inevitably created. This defect can be filled with either free bone graft or vascularized one (Jin et al., 2019).

When a nonvascularized bone graft is put at the nonunion site, the risks of its absorption and failure of the graft to revascularize are high. A bone graft with an intact pedicle of blood supply remains viable; in addition, it unites directly with the recipient bone without necessity of revascularization or replacement by creeping substitution (Obada et al., 2015 and Kumar et al., 2017).

It is also a ready source of vascular osteogenic tissue which sprouts new outgrowths to revascularize the avascular recipient bone tissue. Vascularized bone grafts are usually advocated for failure of conventional techniques. But in cases of nonunion with AVN of proximal pole, most of the surgeons advocate use of primarily vascularized graft. Vascularized bone grafts can be derived from several different locations. The most commonly used bone grafts are from the distal radius (Kumar et al., 2017).

There is no standard treatment of chronic nonunion of the scaphoid, but the technique we used is an accessible method to treat any recurrent pseudarthrosis. The main advantage of this preocedure is that it respects the normal principles of fracture-healing better than a simple placement of a non-vascularised bone graft, in an unfavorable low-vascular bed (Obada et al., 2015).

The healing potential of an ununited scaphoid depends on two factors, i.e. vascularity and stability. Because of its vulnerable blood supply and the loss of retaining ligamentous support, unstable and proximal non-unions of the scaphoid have been associated with decreased rates of union after conventional bone-graft procedures. The rate of success with conventional grafting is lower when the proximal pole of the scaphoid is completely avascular. Revascularisation seems to be faster promoted by the use of vascularised bone grafts than conventional autogenous graft from the iliac crest. Vascularised bone grafts obtained from the distal radius and pedicled by the pronator quadratus have been described by Braun, Leung and Hung, Kawai and Yamamoto (Obada et al., 2015).

The aim of the current study was to assess the effect of pronator quadratus vascularized muscle bone pedicle graft in scaphoid nonunion with fixation.

\section{PATIENTS AND METHODS}

The study was conducted on 20 patients with a history of scaphoid fracture since three months ago and no clinical or radiological signs of healing at Al-Azhar University Hospitals.

\section{Inclusion Criteria:}

Persistent tenderness, incomplete trabecular bridging on three $\mathrm{X}$-ray views and injury that had occurred since 3 months prior to surgery.

\section{Exclusion Criteria:}

Avascular necrosis of the proximal pole, humpback deformity, smoking, midcarpal instability or carpal collapsed and if they had undergone previous surgery for scaphoid fixation with conventional bone graft. 
The study was a prospective clinical trial. An approval of the study was obtained from our local research ethical committee. An informed written consent before participation of the study was collected from every patient.

Patients included in the study were subjected to full history taking and clinical examinations and pre-operative preparation.

\section{Operative technique:}

- A linear incision was made centered over the distal radius and the scaphoid tuberosity.

- The radioscaphocapitate ligament was incised.

- The nonunion site was exposed and the fibrous material was curetted until normal bone was visible.

- In viable proximal fragments bleeding points were seen even with the tourniquet inflated.

- Pronator quadratus muscle's distal insertion over the radius was identified and bone block of $5 \times 10 \mathrm{~mm}$ was outlined close to abductor pollicis longus tendon.

- Graft was separated with a fine osteotome taking utmost care not to detach the muscle from it.

- The muscle was then dissected towards the ulna to secure a $10 \mathrm{~mm}$ thick pedicle.

- In cases, where the muscle was too tight to allow easy transfer of the pedicled bone, the ulnar origin of the muscle was dissected subperiostally from the distal ulna through an additional incision.
- A traction force was applied over the thumb to align the proximal and distal fragments fixed with a Herbert screw. The anterior surface of the scaphoid was made raw both in the proximal and distal fragments. The pedicled bone block was fixed to the raw surface using 3-0 poly glycolic acid suture.

- The vascularity of the graft was verified by inspection of bleeding from it after deflating the tourniquet. The radio scapho capitate ligament was sutured back.

- The skin incision was closed without tension and a long arm cast with the thumb in opposition was applied for 6 weeks, followed by a short cast for next 6 weeks. Physiotherapy and active exercises were started after 3 months.

\section{Post-operatively:}

- Patients were followed up every six weeks and serial radiographs were taken which included postero anterior, lateral and oblique views.

- Union was defined as bony trabeculae crossing the nonunion site and absence of sclerosis at the union site.

- Clinical examination included the assessment of pain with palpation (clinical union), and during rest and activities. ROM was measured using a goniometer.

- Grip strength was assessed using a dynamometer and compared with the uninjured contralateral extremity. Clinical outcome was assessed using the modified Mayo Wrist Score and Disabilities of Arm, Shoulder and Hand score. 


\section{Statistical analysis:}

Recorded data were analyzed using the statistical package for social sciences, version 20.0 (SPSS Inc., Chicago, Illinois, USA). Quantitative data were expressed as mean \pm standard deviation (SD).
Qualitative data were expressed as frequency and percentage. The p-value was considered significant as the following: P-value $\leq 0.05$ was considered significant. 


\section{RESULTS}

The study was conducted on 20 patients with a history of scaphoid fracture since three months ago and no clinical or radiological signs of healing with the mean age $34.27 \pm 11.74$ years and male predominance. Left affection was found in two patients (10\%), while right affection was found in 18 patients $(90 \%)$. Two patients were housewives (10\%), two patients were employers (10\%), 10 patients were manual workers $(50 \%)$ and 6 patients were farmers $(30 \%)$. The duration of symptoms before surgery ranged from 4 to 12 weeks. Twelve patients had symptoms $4-8$ weeks (60\%), 6 patients had symptoms from 8 to 12 weeks (30\%) and two patients had symptoms 1-4 weeks (10\%). There were six patients had proximal pole fracture $(30 \%)$ and $14(70 \%)$ patients had waist fracture. There were four patients had sclerotic pseudarthrosis (20\%) and 16 $(80 \%)$ patients had fibrous Nonunion (Table 1).

Table (1): Distribution of the studied cases according to age, sex, affected side, occupation, duration of symptoms, site of fracture and type of nonunion

\begin{tabular}{|c|c|c|}
\hline $\begin{array}{ll}\text { Parameters } & \text { Cases } \\
\end{array}$ & No. & $\%$ \\
\hline \multicolumn{3}{|l|}{ Gender } \\
\hline Female & 8 & 40 \\
\hline Male & 12 & 60 \\
\hline \multicolumn{3}{|l|}{ Age (years) } \\
\hline$\leq 40$ & 14 & 70 \\
\hline$>40$ & 6 & 30 \\
\hline Min. - Max. & \multicolumn{2}{|c|}{$22.0-45.0$} \\
\hline Mean \pm SD. & \multicolumn{2}{|c|}{$34.27 \pm 11.74$} \\
\hline Median & \multicolumn{2}{|c|}{33.0} \\
\hline \multicolumn{3}{|l|}{ Side } \\
\hline Left & 2 & 10 \\
\hline Right & 18 & 90 \\
\hline \multicolumn{3}{|l|}{ Occupation } \\
\hline Employee & 2 & 10 \\
\hline Farmer & 6 & 30 \\
\hline Housewife & 2 & 10 \\
\hline Manual worker & 10 & 50 \\
\hline \multicolumn{3}{|l|}{ Duration of symptoms } \\
\hline $1-4$ weeks & 2 & 10 \\
\hline $4-8$ weeks & 12 & 60 \\
\hline $8-12$ weeks & 6 & 30 \\
\hline \multicolumn{3}{|l|}{ Site of fracture } \\
\hline Proximal pole & 6 & 30 \\
\hline Waist & 14 & 70 \\
\hline \multicolumn{3}{|l|}{ Type of Nonunion } \\
\hline Fibrous & 16 & 80 \\
\hline Sclerotic & 4 & 20 \\
\hline
\end{tabular}


The mean flexion was 570 (range, $45^{\circ}-$ $60^{\circ}$ ). The mean extension was $59^{\circ}$ (range, $50^{\circ}-65^{\circ}$ ). Ulnar deviation averaged $32^{\circ}$ (range, $25^{\circ}-38^{\circ}$ ) and radial deviation averaged $12^{\circ}$ (range, $8^{\circ}-16^{\circ}$ ). The mean grip strength was $67 \%$ (range, $75 \%$ - 73\%) compared with that of the contralateral healthy extremity.

The mean flexion was $81^{\circ}$ (range, $70^{\circ}-$ $90^{\circ}$ ). The mean extension was $74^{\circ}$ (range, $\left.65^{\circ}-80^{\circ}\right)$. Ulnar deviation averaged $39^{\circ}$ (range, $30^{\circ}-45^{\circ}$ ) and radial deviation averaged $18^{\circ}$ (range, $15^{\circ}-20^{\circ}$ ). The mean grip strength was 99\% (range, 95\% 100\%) compared with that of the contralateral healthy extremity, which had improved from a preoperative mean of $67 \%$ (Table 2).

Table (2): Distribution of the studied cases according to preoperative and postoperative clinical results

\begin{tabular}{|l|c|c|c|c|}
\hline \multirow{2}{*}{ Results } & \multicolumn{2}{|c|}{ Preoperative } & \multicolumn{2}{c|}{ Postoperative } \\
\cline { 2 - 5 } Distributions & Mean & Range & Mean & Range \\
\hline The mean Flexion & $57^{\circ}$ & $45-60$ & $81^{\circ}$ & $70-90$ \\
\hline The mean Extension & $59^{\circ}$ & $50-65$ & $74^{\circ}$ & $65-80$ \\
The mean Radial deviation & $12^{\circ}$ & $8-16$ & $18^{\circ}$ & $15-20$ \\
The mean Ulnar Deviation & $32^{\circ}$ & $25-38$ & $39^{\circ}$ & $30-45$ \\
The mean Grip strength (\% of & & & & \\
healthy side) & $67 \%$ & $57-73$ & $99 \%$ & $95-100$ \\
\hline
\end{tabular}

There were six patients $(30 \%)$ had 10 14 weeks, 10 patients (50\%) had 14-18 weeks and four patients (2\%) had more than 18 weeks to return to work. They achieved bony union in a mean of 12.5 weeks. Regarding to functional results, 12 patients were excellent $(60 \%)$, four patients were good (20\%) and two patients were moderate while no patients were poor. Regarding to Overall satisfaction there were all the patients satisfied about their results (Table 3).

Table (3): Distribution of the studied cases according to Duration until returns to work (weeks), functional results (Mayo Wrist score) and overall satisfaction

\begin{tabular}{|l|c|c|}
\hline Cases & No. & $\%$ \\
\hline Parameters & & \\
\hline $10-14$ & 6 & 30 \\
\hline $14-18$ & 10 & 50 \\
$>18$ & 4 & 20 \\
\hline Functional results (Mayo Wrist score) & & \\
\hline Excellent & 12 & 60 \\
Good & 4 & 20 \\
\hline Moderate & 2 & 10 \\
Poor & 0 & 0 \\
\hline Overall satisfaction & 20 & \\
\hline Satisfactory & 0 & 0 \\
\hline Non satisfactory & & \\
\hline
\end{tabular}




\section{DISCUSSION}

The aim of work of the current study was to assess the effect of pronator quadratus vascularized muscle bone pedicle graft in scaphoid nonunion with fixation. To elucidate this aim 20 patients with a history of scaphoid fracture since three months ago and no clinical or radiological signs of healing.

The mean age of the studied patients in the current study was $34.27 \pm 11.74$ years with all of the studied patients noted no complications wither early or late and returned to their previous level of activity. Age has been identified as a factor of poor prognosis by other authors (Merrell \& Wolfe 2012 and Chang et al., 2013).

In the present study, all the cases achieved bony union (100\%) in a mean of 12.5 weeks. There was improvement in mean radiolunate and scapholunate angles. Average range of motion and modified Mayo score. There were no early complications of surgical site infection or sensory disturbances in the area of the radial nerve. There were also none late septic complications. No radiographic progression of arthritis was noted in any patient within the available follow-up time. All the ten patients returned to their previous level of activity. All the patients were satisfied with the late clinical and functional results.

Early radiographies following a scaphoid vascularised graft may be inacurrate and could show a delay union or nonunion inspite of a united fracture. Scaphoid vascularised grafts may have a markedly delayed radiographic healing time (Morin et al., 2011).
Dorsal pedicled distal radius VBGs are used for proximal scaphoid nonunions, while volar grafts are preferred for nonunions in the waist region of the scaphoid and in nonunions with humpback deformity (Karaismailoglu et al., 2020).

The volar approach minimises damage to the blood supply and facilitates correction of any flexion deformity. Union rates have been reported to be $20 / 22$, 21/26 (in 7 to 18 years), 147/151 (in one to 10 years), and $38 / 44$ (in 12 to 163 months) (Raju and Kini 2011).

A rate of union of $90 \%$ was reported after using of a free vascularised iliaccrest wedge graft for the treatment of scaphoid nonunion with an avascular proximal pole (Obada et al., 2015). Henry (2011) reported a successful graft based on a 1, 2 intercompartimental supraretinacular artery pedicle in the treatment of scaphoid collapse and osteonecrosis.

Several other pedicled vascularised grafts have been described for the treatment of persistent scaphoid nonunion, but the use of vascularised graft from the volar and ulnar aspect of the distal part of the radius supplied by the palmar carpal artery has been reported to have excellent rates of union (Jones et al., 2012).

Viability and stability of the fragments are essential for obtaining consolidation of pseudarthrosis. The base principle is to treat avascular necrosis by increasing the vascularity of the bone. It is unclear if enough osteogenic bone survives after a nonvascularised bone graft method. Laboratory studies of vascularised and nonvascularised grafts have demonstrated that the former are associated with earlier 
union and with greater strength and stiffness between six weeks and six month postoperatively (Obada et al., 2015).

Lee et al. (2015) reported on patients with scaphoid nonunion who were treated with a pronator quadratus pedicled vascularized bone graft and a headless compression screw. They achieved bony union in all the patients a mean of 11.5 weeks. There was an improvement in mean radiolunate and scapholunate angles. Average range of motion and modified Mayo score and DASH score had improved.

Goel et al. (2017) reported on cases of nonunion scaphoid with pronator quadratus vascularized bone graft. Herbert and Alnot classification was used and postoperative evaluation done by scaphoid outcome score. The mean follow-up period was 22 months.

Obada et al. (2015) reported on ununited scaphoid fractures and treated with pronator quadratus pedicled bone graft and Herbert-screw or Kirschnerwires fixation. They achieved radiographic consolidation in all cases after an average of 9.8 weeks.

The osteosynthesis has been used to increase the stability of bone fragments and bone graft. The use of the Herbertscrew was initially reported by Herbert and Fischer, who also reported higher success of nonunions treatment in association with bone graft. Numerous studies have reported the better results of Herbertscrew fixation with bone grafting with increased rates of union and range of motion (Huang et al., 2011).

Insertion of Herbert screw requires special equipment and high technical skills. Another disadvantage is that it violates scaphotrapezial joint, but the great advantage is that it provides more rigid fixation, promotes early active motion and compression than Kirschner wires (Obada et al., 2015).

Accurate placement of the Herbert screw using a free-hand technique is challenging; flexing the wrist and using the axis of the thumb as a guide may prevent malposition of the implant. However, fluoroscopic confirmation of placement of the guidewire is not possible, because the wrist is flexed. When Herbert-screw fixation is combined with bone grafting, patients with scaphoid non-union achieved union (Raju and Kini, 2011).

Iliac crest is the most common site for the harvest of autologous nonvascularized bone graft for most orthopedic procedures. Its osteogenic and mechanical properties are well proven, and a large quantity of graft can be harvested. But in comparison, distal radius graft is easier to harvest. This involves the same extremity, and a smaller incision is needed. Although iatrogenic fracture is a potential complication while harvesting graft from the distal radius, a corticocancellous graft harvested from the middle part of distal radius with gentle hammering will avoid this complication (Goyal et al., 2013). We have never encountered such problem in any of our cases.

Although the conventional Matti-Russe graft remains an excellent option, many studies reported better consolidation rates using vascularized bone graft: union was achieved in $70 \%$ to $90 \%$ of nonvascularized grafts (Chantelot et al., 2010) and more than $90 \%$ of vascularized 
grafts (Dailiana et al., 2010 and Malizos et al., 2011).

Munk and Larsen (2014) confirmed these findings in a metaanalysis of cases of scaphoid non-union, with an $80 \%$ consolidation rate for non-vascularized bone graft without osteosynthesis, 84\% with osteosynthesis, and $91 \%$ for vascularized graft. In non-union with avascular necrosis of the proximal pole, however, surgeons seem to agree that a primary vascularized graft is the best conservative management, due to the very poor consolidation rate obtained with nonvascularized grafts $(<50 \%)$ (Chantelot et al., 2010 and Jones et al., 2012). Dailiana et al. (2010) reported that union on MRI was achieved faster with a vascularized graft.

\section{CONCLUSION}

Volar vascularized bone grafts is an easy method and provides excellent results while needing no special equipment. It as primary treatment procedure for scaphoid non-union irrespective of status of vascularity of proximal pole due to the quality of the functional results and the speed of consolidation. Bone grafting is the mainstay treatment for non-union scaphoid. Vascularized bone grafts using pronator quadratus osteomuscular flaps have proved to be more biological and more successful treatment option.

\section{REFERENCES}

1. Chang MA, Bishop AT, Moran SL and Shin AY (2013): The outcomes and complications of 1,2-intercompartmental supraretinacular artery pedicled vascularized bone grafting of scaphoid nonunions. J Hand Surg (Am)., 31(3):387-96.
2. Chantelot C, Frebault C, Limousin M, Robert G, Migaud $H$ and Fontaine $C$ (2010): Long-term outcome of non-vascularized grafts for carpal scaphoid nonunion: 58 cases with 8.8-year follow-up. Rev Chir Orthop Reparatrice Appar Mot., 91(8):724-31.

3. Dailiana ZH, Malizos KN, Zachos V, Varitimidis SE, Hantes $M$ and Karantanas A (2010): Vascularized bone grafts from the palmar radius for the treatment of waist nonunions of the scaphoid. J Hand Surg., 31(3):397-404.

4. Goel V, Valecha N, Bhuyan BK, Sharma SK and Singh V (2017): Nonunion scaphoid treated with vascularized pronator quadratus osteomuscular transposition flap: A review of 11 cases. J Orthop Traumatol Rehabil., 9:10611.

5. Goyal T, Sankineani SR and Tripathy SK (2013): Local distal radius bone graft versus iliac crest bone graft for scaphoid nonunion: A comparative study. Musculoskelet Surg., 97:109-14

6. Henry M (2011): Collapsed scaphoid nonunion with dorsal intercalated segment instability and avascular necrosis treated by vascularised wedge-shaped bone graft and fixation. J Hand Surg Eur., 32: 148-54.

7. Huang Y, Liu Y and Chen T (2011): Longterm results of scaphoid nonunion treated by intercalated bone grafting and Herbert's screw fixation - a study of 49 patients for at least five years. Int Orthop., 33(5): 1295-1300.

8. Jin D, Fu $S$ and Wu $T$ (2019): Tissue Engineering and Orthopedic Microsurgery. Microsurgical Orthopedics, 13: 521-535.

9. Jones DB, Burger H, Bishop AT and Shin AY (2012): Treatment of scaphoid waist nonunions with an avascular proximal pole and carpal collapse - A comparison of two vascularized bone grafts. J Bone Joint Surg Am., 90(A): 2616-25.

10. Karaismailoglu B, Guven $M$ and Erenler $M$ (2020): The use of pedicled vascularized bone grafts in the treatment of scaphoid nonunion: clinical results, graft options and indications. EFORT Open Rev., 5:1-8. 
11. Kumar M, Kumar R and Ranjan R (2017): Results of pronator quadratus pedicle bone graft as primary procedure for treatment of scaphoid nonunion. International Journal of Orthopaedics Sciences, 3(3): 1008-1012.

12. Lee SK, Park JS and Choy WS (2015): Scaphoid fracture nonunion treated with pronator quadratus pedicled vascularized bone graft and headless compression screw. Annals of Plastic Surgery, 18:178-183.

13. Malizos KN, Zachos V, Dailiana ZH, Zalavras C, Varitimidis $S$ and Hantes $M$ (2011): Scaphoid nonunions: management with vascularized bone grafts from the distal radius: a clinical and functional outcome study. Plast Reconstr Surg., 119(5):1513-25.

14. Merrell GA and Wolfe SW (2012): Slade 3rd JF. Treatment of scaphoid nonunions: quantitative meta-analysis of the literature. J Hand Surg (Am)., 27(4):685-91.

15. Morin P, Reindl R, Berry GK, Harvey EJ (2011): Incorrect radiographic evaluation after vascularized bone grafting for scaphoid fracture or nonunion. Can J Plast Surg., 19(1): 6-9.

16. Munk B and Larsen CF (2014): Bone grafting the scaphoid nonunion: a systematic review of 147 publications including 5,246 cases of scaphoid nonunion. Acta Orthop Scand., 75(5): 618-29.

17. Obada B, Serban A, Badauta M, Obada AT and Costea D (2015): Treatment of nonunion of the scaphoid with pronator quadratus pedicled bone graft. JOTSRR., 1(37): 22-30.

18. Raju PK and Kini S (2011): Fixation techniques for non-union of the scaphoid. Journal of Orthopaedic Surgery, 19(1):80-84. 


\section{تصليح الكسور الفير ملثئمة بالعظمة الزورقية بواسطة رقمة عنيقية

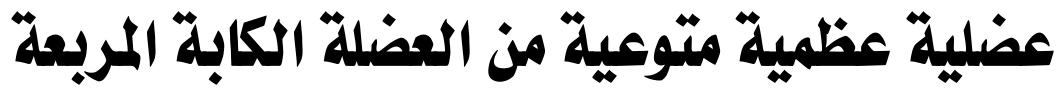 \\ أحمد محمد النجار، إبراهيم أحمد حسين، محمد إبراهيم أبو السعود ه}

قسم جراحة العظام ، كلية الطب ، جامعة الأزهر

E-mail: ahmed.gaara88@gmail.com

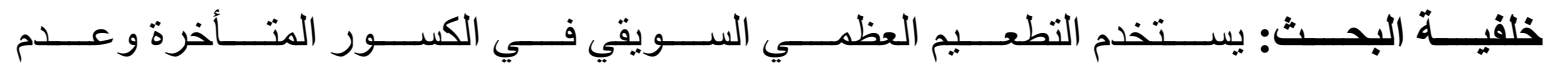

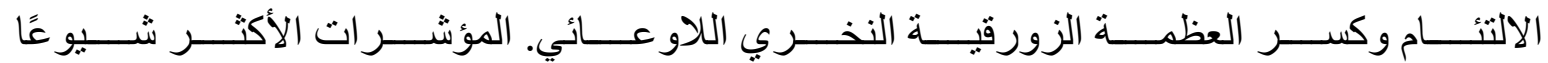

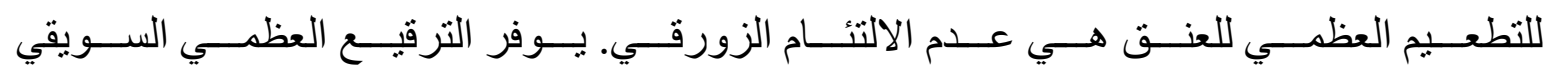

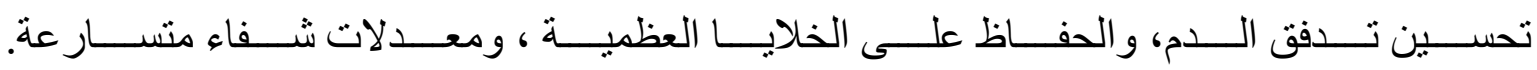

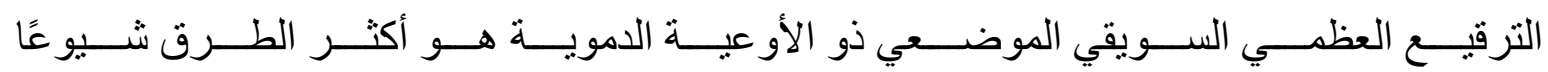
والاقل تطلبا من الناحية الفنية مع أثار جانبية أقل.

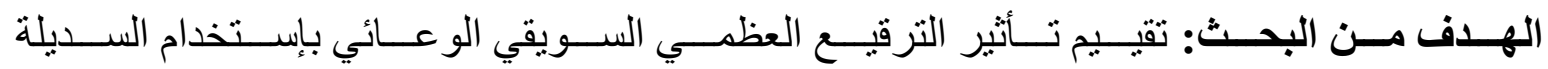
العظمية العضلية الرباعية في عدم الالتئام الزورفي مع التثبيت.

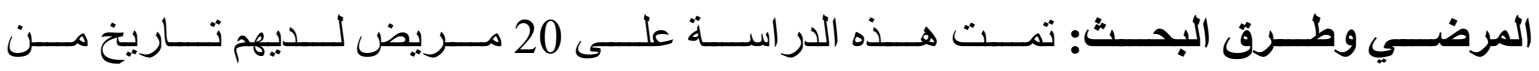
كسور الزورق منذ ثلاثة أنشهر ولا توجد علامات سريرية أو إنشعاعية للثفاء.

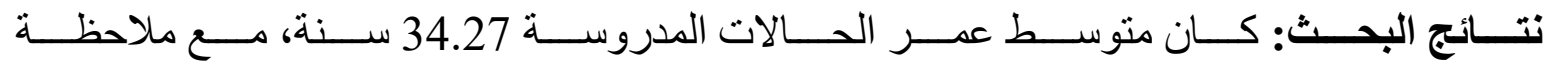

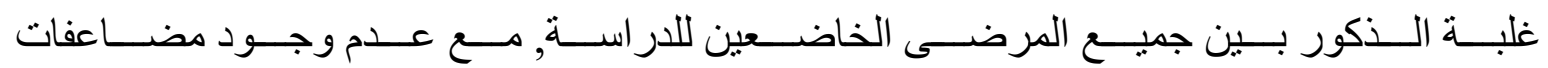

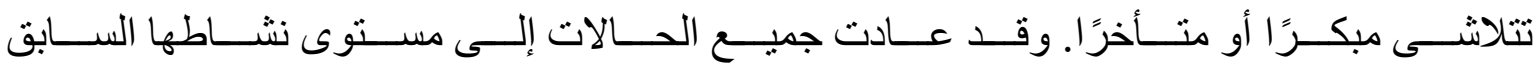

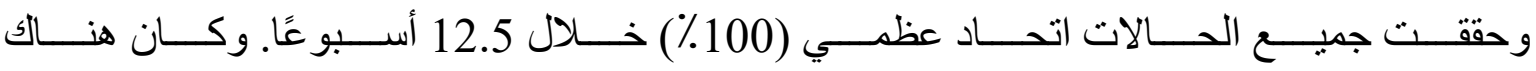

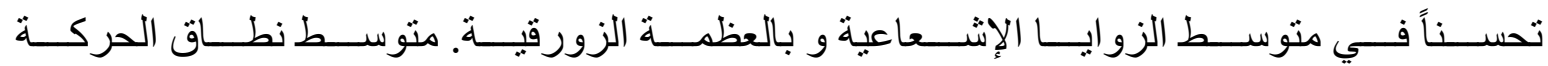

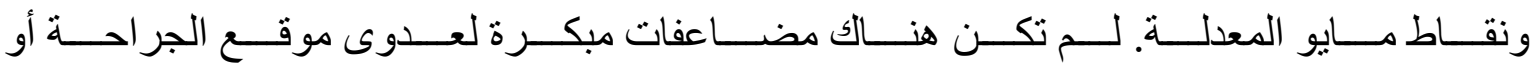

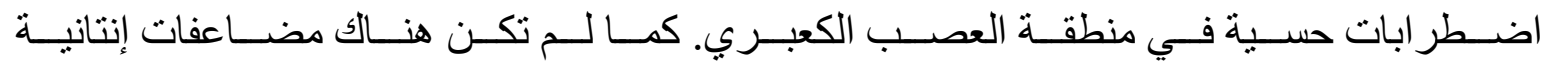

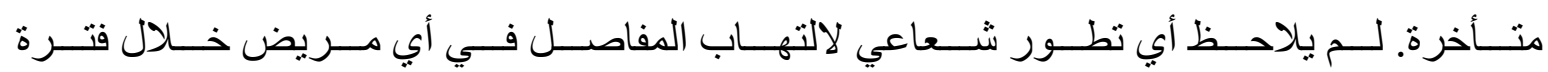

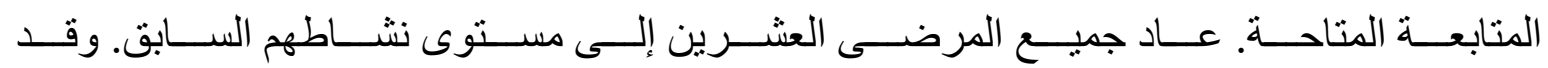
كان جميع المرضى ر اضين عن النتائج السريرية و الوظيفية المتأخرة. 


\section{AHMED MOHAMED EL-NAGGAR et al.,}

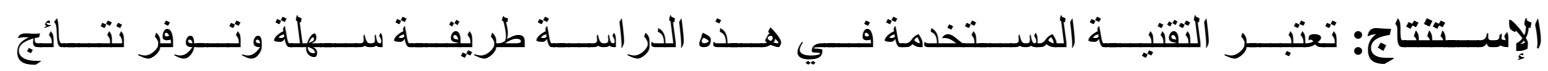

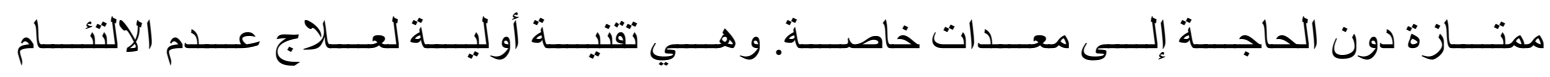

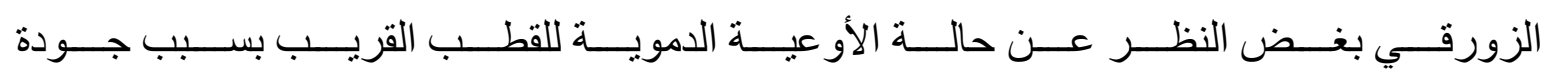

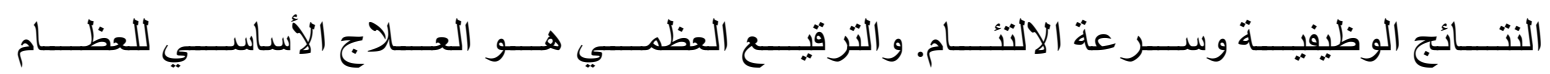
الزورقية غير ملتئمة.

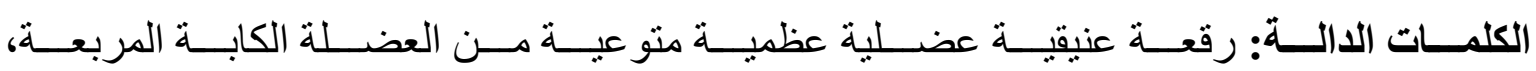
الكسور الغير ملتئمة بالعظمة الزورقية مع التثبيت. 